\title{
Design and analysis of PM motor with semi-circle stator design using 2D-finite element analysis
}

\author{
Mohd Luqman Mohd Jamil, Kwang T. C., Auzani Jidin \\ Power Electronics \& Drive Research Group (PEDG), Universiti Teknikal Malaysia Melaka, Malaysia
}

\begin{abstract}
Article Info
ABSTRACT

Article history:

Received Nov 23, 2018

Revised Dec 15, 2018

Accepted Dec 20, 2018

This paper presents a basic approach to reduce an overall weight of selected PM motor. The approach is not based on normal sizing step by keeping the overall design in symmetry dimension, but by introducing semi-circle stator design.The investigation takes 12-slot/10-pole motor as a subject due to it symmetric winding disposition. Two designs are included, both having identical semi-circle stator but different in rotor configuration. Design 1 has a standard rotor design that equipped with 10-pole while Design 2 has a semicircle rotor design following the stator design. This inherently result an even

Keywords:

Overall weight

PM motor number of pole i.e. 5. From the investigation using 2D-Finite Element Analysis, an overall weight in PM motor can be theoretically reduced by having asymmetric design dimension. Due to a semi-circle rotor design and even number of rotor pole, the Design 2 results poor back-emf and poor torque performance than the Design 1. A proper design procedure that includes parameters optimization and intelligent switching for optimum current excitation is required to restore the desired torque of Design 1.
\end{abstract}

Copyright () 2019 Institute of Advanced Engineering and Science. All rights reserved.

\section{Corresponding Author:}

Mohd Luqman Mohd Jamil,

Power Electronics \& Drives Research Group (PEDG)

UniversitiTeknikal Malaysia Melaka,

Hang Tuah Jaya, 76100 Durian Tunggal, Melaka, Malaysia.

Email: luqman@utem.edu.my

\section{INTRODUCTION}

Nowadays, electrical machines have been widely used in many applications starting from consumer appliances up to heavy automated industrial systems. With the rise of 4.0 Industrial Revolution, electrical machines are still the back-bone for intelligent robotic systems as there is a need for accurate mechanical movement in term of speed and positioning. The robotic systems involve with integrations of many disciplines such as power electronic and electrical drives, machine design, kinematics and artificial intelligentincluding specifictechnological requirement for the desired design.

From machine design perspective, suitable motor selection is the main key which would result high efficiency, low cost, light weight and better dynamic performance. Brushed DC motor, Brushlesss DC motor and Stepper motor are common electricalmachines used in robotic system.

For a radial flux machine, Brushed DC motors consist of stator and rotorthatare wound with copper wire and equipped with a commutation system. The system consists of commutator segments and a pair of carbon brush that allow the current reversion. The wound stator which field winding is located generates main magnetic flux while the wound rotor which locates armature winding allows induced voltage exists.The armature winding is end connected to commutator and brushes to reduce electrical losses and excessive wear commutator segment [1].Brushed DC motors have offered good speed-torque performance, reliability, inexpensive, simple construction and wide range speed controllability [2]. However, these motors result low efficiency and required periodic maintenance due to the presence of brushes [3]. Common controllers implemented in Brushed DC motors for robotic applications are PID [4-6] and fuzzy logic controller [7]. 
Stepper motor working principle is based on current pulse excitation that resultsmechanical rotation. They have high torque at low speed, excellent response, controllable acceleration and able to be gearless as compared to the brushed DC motors [8]. The classification of stepper motors rely on stator and rotor construction. Harshvardhan R. et al compares various type of stepper motors in term of construction, principle, phase and excitation mode [9].Generally, stepper motors are categorized into variable-reluctance, permanent magnet and hybrid types as shown in Figure 1.

The variable-reluctance motors only have stator winding where DC source is connected while rotor is made of slotted steel lamination which carries no windings. Permanent magnet stepper motors are equipped with permanent magnet mounted on rotor body and operate based on attraction or repulsion phenomena between rotor and stator flux. While hybrid stepper motors are the combination of variable-reluctance and permanent magnet types to develop superior step resolution, torque and speed performance. The stator coils in hybrid stepper motors are wound in alternate pole that equipped with permanent magnets on rotor which offer economical, small and very simple design. Variable reluctance motors and hybrid stepper motors have better torque production and accurate position. On top of that, hybrid stepper motors have smaller overshoot, oscillatory response and settling time resulting more precise position [10]. Stepper motors with smaller step pulse angle have better position and lower cost [11]. In overall, stepper motors have low efficiency, low torque to inertia ratio and required high current consumption compared to brushless DC machines. Most of these motors are interfaced with microcontroller for efficient performance in robotic applications [12-14].

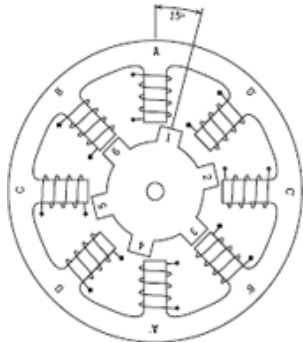

a) Variable-reluctance

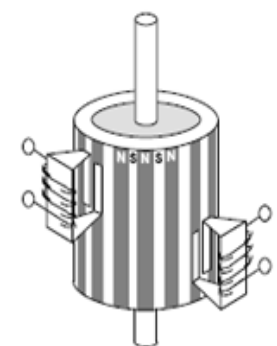

b) Permanent magnet

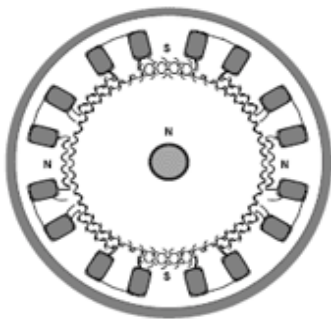

c) Hybrid

Figure 1. Various type of stepper motors [15]

Permanent magnet (PM) brushless motors are electronically commutated, offerhigh efficiency [16], reliability, low volume [17], noiseless operation, high output torque at rated low speed [18] and also no periodic maintenance as compared to conventional DC motors [19]. PM motors gain popularity in industries due to small hardware size, light weight and simpler gearing system [20]. Priti presents the criteria selection for reliable and efficient PM machines for various applications [21]. Criteria selection such as output power, output torque, rated speed, switching scheme at different loads are mainly considered for superior performance. PM machines are categorized into two operating modes which depend on back-emf waveform as in Figure 2. For DC mode (BLDC), the motors have trapezoidal back-emf and trapezoidal excitation current profile while the AC mode (BLAC) results the motors to have both back-emf and current waveforms in sinusoidal shape. The BLDC motors generally have superioroutput torque performance and high efficiency over BLAC motors for an identical motor geometry [22]. However, BLDC motors may have higher torque ripple and lower output power density than the BLAC motorsin some cases [23-24].

For an axial flux configuration, high torque-density, high efficiency and shorter axial length are possible to achieve [25]. However, complex construction, high torque ripple and poor power-density in various load condition are inherited. Conventionally, the radial flux Brushless PM motors are constructed with permanent magnet on rotor. This configuration has simple construction, more robust, better torque at high load capacity, high flux-density and lower cogging torque than the axial flux machines [26-27]. The slotted and slotless stators are made up of stacked steel laminations with winding arranged within stator geometry. In slotted BLDC motors, the windings are configured among slots and uniformly distributed over stator peripheral area. Better torque performance i.e. high average torque and minimum torque ripple can be achieved by having proper shape of slots in PM machines [28]. While slotless machines are wound in cylinder between stator and rotor leading to a compact design, excellent power-to-weight ratio, lightweight, lower cogging torque and smaller vibration than slotted type [29-30]. However, slotless type results low average torque, longer axial length, thicker magnet, costly and less efficient [31]. The rotor is constructed with permanent magnets (PMs) with alternate North and South poles for stator poles winding excitation. Due to high coercivity field strength 
about 800 to $1050 \mathrm{kA} / \mathrm{m}$, high remanence magnetic flux of $1.1 \mathrm{~T}$ to $1.3 \mathrm{~T}$ and cheaper than samarium cobalt magnet, Neodymium Iron Boron (NdFeB) has gained high popularity [32-33]. Examples of various PM rotors are shown as in Figure 3 [24], [34]. The interior permanent magnet rotor type results structure complexity leading to expensive manufacturing cost as compared to the surface mounted magnet configuration.

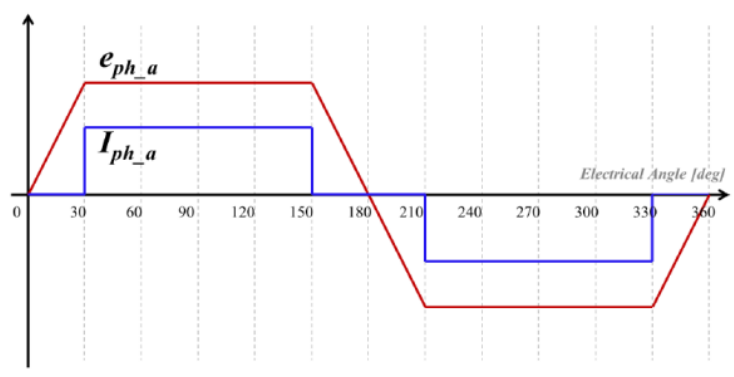

a) BLDC motor

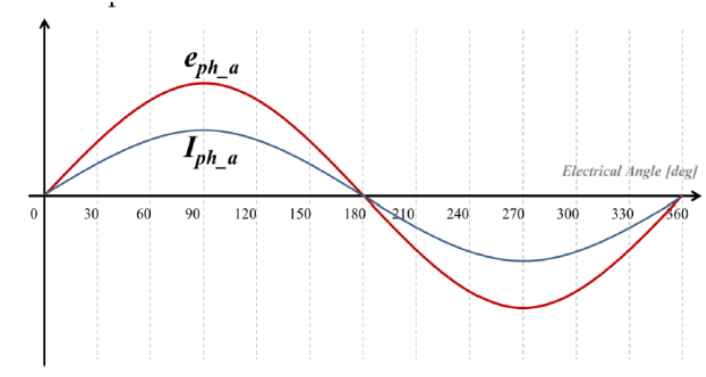

b) BLAC motor

Figure 2. Type of operating modes in PM machines

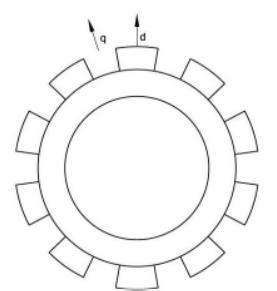

a) Surface mounted magnet

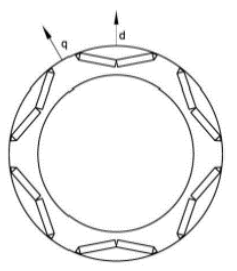

b) Interior permanenmagnet

Figure 3. Types of PM rotor configuration

BLDC motor drives system motors requires three-phase inverter and rotor position detection device for a desired rotation. For position detection system, an enclosed cap consists of three hall sensors fitted on pcbis fixed on non-driving end. The sensors are properly positioned to ensure commutation takes place sequentially and results phase displacement of $120^{\circ}$ electrical [35-36]. There will be two windings energizing instantly and alternate conduction among all windings with respect to hall sensors sensing sequence [37]. Thanks to technology advancing, sensorless rotor position with improvement detection in PM motors are introduced for overall low-cost systems [38-39]. While common basic controllers used for BLDC motors in robotic application still based on PID [40-41], fuzzy logic controller, fuzzy PID controller [42] and adaptive fuzzy PID controllers [43].

Some robotic application systems faced low power-to-weight ratio, high power consumption, bulky size and poor safety system. For a specific application, a lightweight designwithout performance degradation is needed and proposed in this article. A new motor design having an asymmetric stator or semi-statordesign is presented. The design aims to reduce overall machine weight without reducing average torque as measured in the earlier developed prototype [44]. The investigation is carried out by using 2-D Finite-Element Analysis.

\section{MATHEMATICAL MODEL OF BLDC MOTOR}

An equivalent circuit of BLDC motor is shown in Figure 4. The motor connection is configured in star-connection and fed by three phase voltage source inverter. The motor is excited with one of modes which influenced by the back-emf profile $\left(e_{a}\right)$ as shown in Figure 2. Some general assumptions shall be considered in modelling of PM machines are described in [45-47]. 


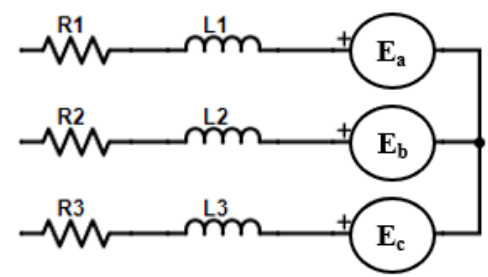

Figure 4. Equivalent circuit for BLDC motor

The individual armature winding voltages of each phase are as follows:

$$
\begin{aligned}
& V_{a}=R i_{a}+L \frac{d i_{a}}{d t}+e_{a} \\
& V_{b}=R i_{b}+L \frac{d i_{b}}{d t}+e_{b} \\
& V_{c}=R i_{c}+L \frac{d i_{c}}{d t}+e_{c}
\end{aligned}
$$

where $R_{a}, R_{b}$ and $R_{c}$ are individual armature phase resistance, $L_{a}, L_{b}$ and $L_{c}$ are individual armature phase inductance, while $i_{a}, i_{b}$ and $i_{c}$ are individual armature phase current respectively. A simplified model is then expressed in matrix form as in equation (4). The phase back-emfs as in equations (5), (6) and (7) respectively are developed once the rotor rotates and they are apart by 120 electrical degree. The dynamic equation of a developed electromagnetic torque in PM motor is expressed as in equation (8). Note that the torque developed is contributed by two phase conduction at an instant. The $e_{a}, e_{b}$ and $e_{c}$ are individual phase back-emfs, while $k$, $\theta, \omega, J, B$ and $T_{L}$ is back-emf constant, electrical angle, rotor mechanical rotor speed, rotor inertia, damping constant and load torque respectively.

$$
\begin{aligned}
& {\left[\begin{array}{l}
V_{a} \\
V_{b} \\
V_{c}
\end{array}\right]=\left[\begin{array}{ccc}
R+p l & 0 & 0 \\
0 & R+p l & 0 \\
0 & 0 & R+p l
\end{array}\right]\left[\begin{array}{l}
i_{a} \\
i_{b} \\
i_{c}
\end{array}\right]+\left[\begin{array}{l}
e_{a} \\
e_{b} \\
e_{c}
\end{array}\right]} \\
& e_{a}=k \omega f(\theta) \\
& e_{b}=k \omega f\left(\theta-\frac{2 \pi}{3}\right) \\
& e_{c}=k \omega f\left(\theta+\frac{2 \pi}{3}\right) \\
& T_{c}=J \frac{d \omega}{d t}+T_{L}+B \omega
\end{aligned}
$$

\section{PROPOSED DESIGN OF BLDC MOTOR}

A12-slot/ 10-pole, BLDC motor which slot-number and pole-number configuration belongs to Ns= $2 \mathrm{p} \pm 2$ as tabulated in Table 1 is investigated (actual design). The motor layout which initially has a winding factor, $k_{w}$ of 0.966is shown in Figure 5(a). It is initially designedfor a high torque performance of $10 \mathrm{Nm}$ at 100 rpm rated speed. In the early design stage, saturation effect is ignored when machine sizing is carried out. All designs are then analysed by using 2D-Finite Element Analysis where the saturation effect is taken into account. The lamination steel and rare earth magnet are made of silicon steel and $\mathrm{NdFeB}$ respectively. The 
NdFeBmagnet type of $1.2 \mathrm{~T}$ remnant and paralelly magnetized is mounted on rotor surface. With the spirit of reducing overall motor weight, the modification of stator and rotor structure has been investigated. The investigation as shown in Figure 5(a-b) is based on two modification types i.e. semi-stator andsemi-rotor. Prediction of open-circuit flux density, phase back-emf, cogging torque and static electromagnetic torque are included for comparison purpose. The idea of Design 1 and Design 2 is to remove partial stator dimension leading to semi-stator design. The slot-number is then become 6 instead of 12. Since the original slot-number is even, the remaining slot-number is still an even number and the remaining armature coils belong to the phases as origin. However, Design 2 have different rotor design as the pole-number reduces to 5 to align with the stator design which results in symmetric cutting between stator and rotor. Figure 6 compares coil phase selection between original 12-slot/10-pole machine and new modified designs. As half-stator is implemented, a number of coils including surrounding stator iron body is removed. However the mmf vectors for among each remaining phase remains symmetry i.e. $120^{\circ}$ electrical degree apart. The remaining coils set are still belong to phase A, B and C, marked with red, yellow and blue colour respectively.

Table 1. Design specifications for actual 12-slot/10-polemotor

\begin{tabular}{cc}
\hline \multicolumn{2}{c}{ Parameter Specifications } \\
\hline Supply voltage $(\mathrm{V})$ & 24 \\
Rated torque $(\mathrm{Nm})$ & 10 \\
Rated speed $(\mathrm{rpm})$ & 100 \\
Stator outer diameter $(\mathrm{mm})$ & 120 \\
Rotor outer diameter $(\mathrm{mm})$ & 72 \\
Axial length $(\mathrm{mm})$ & 20 \\
Magnet thickness $(\mathrm{mm})$ & 5 \\
Airgap length & 1 \\
Slot opening & 1.1 \\
Tooth tip thickness & 3.3 \\
Rated current $(\mathrm{A})$ & 10 \\
Magnetization type & Parallel \\
Operating mode & BLDC \\
\hline
\end{tabular}

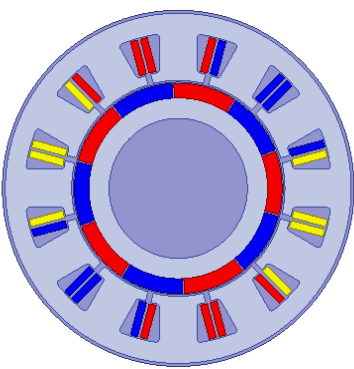

a) 12-slot/10-pole

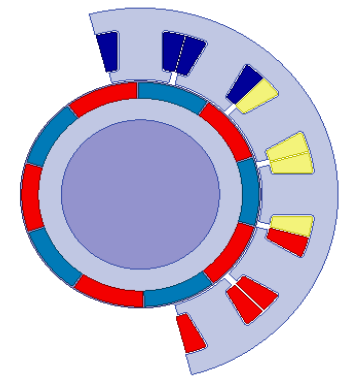

b) Design 1

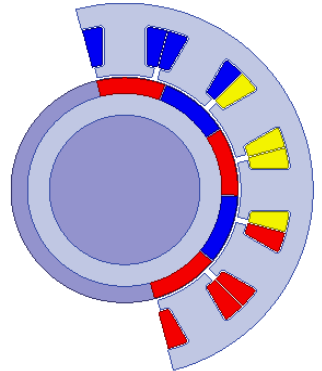

c) Design 2

Figure 5. PM motor structures

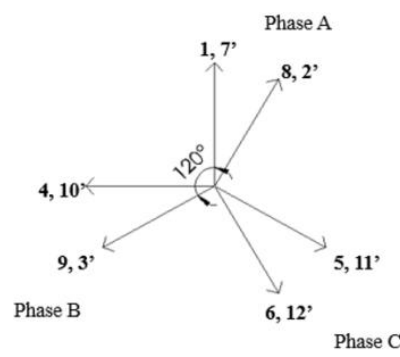

a) 12-slot/10 pole

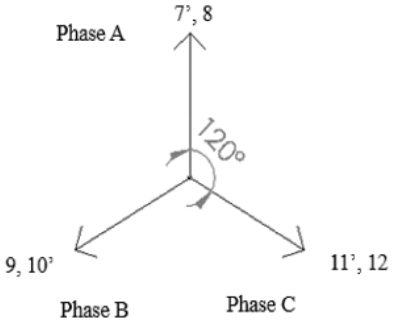

b) Design 1 and Design 2

Figure 6. Coil mmf vectors in PM motor 


\section{RESULTS AND ANALYSIS}

\subsection{No-load Flux-density}

Figure 7 depicts permanent magnet flux-linkages and flux-densities at no-load condtion. Since the pole number, $2 p$ is 10 , there is 5 cycles of flux-linkage and and flux-density for a complete 1 mechanical rotation. For the actual design, although the flux-linkage could be indentified as sinusoid, the no-load fluxdensity profile does not directly related by a cosine function which supposed to have similar sinusoid waveform. However, this situation does not against the faradays's law. The peak flux-linkage of actual design is $0.14 \mathrm{~Wb}$, it reduces to $0.06 \mathrm{~Wb}$ with an almost $60 \%$ reduction when Design 1 and Design 2 are implemented. Severe result is obtained via Design 2 as an asymmetric or non-uniform profile of flux-linkageand no-load flux-density exist. A common non-uniform peak of no-load flux-density occurs mainly due to slotting effect. The no-load flux-densities in Design1 and Design 2 result strange profiles between 0 to $180^{\circ}$ mechanical angles. This is because of dissapearence of coil sets and reduction of pole numbers. Figure 8 compares flux saturation levels for all designs. The blue (dark) areais the area of zero flux-density.

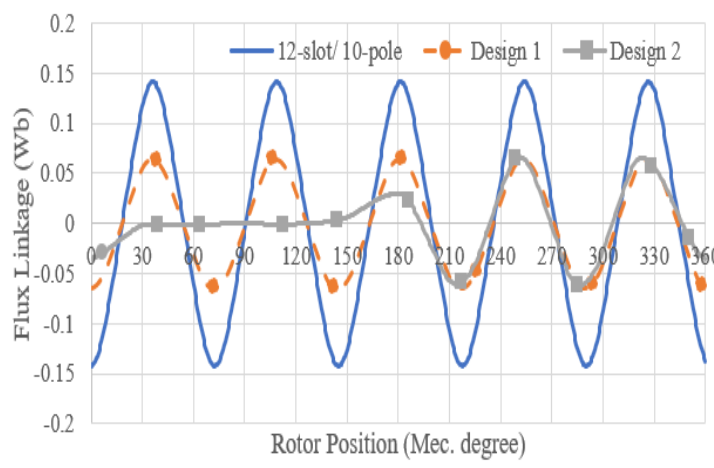

a) Flux-linkage

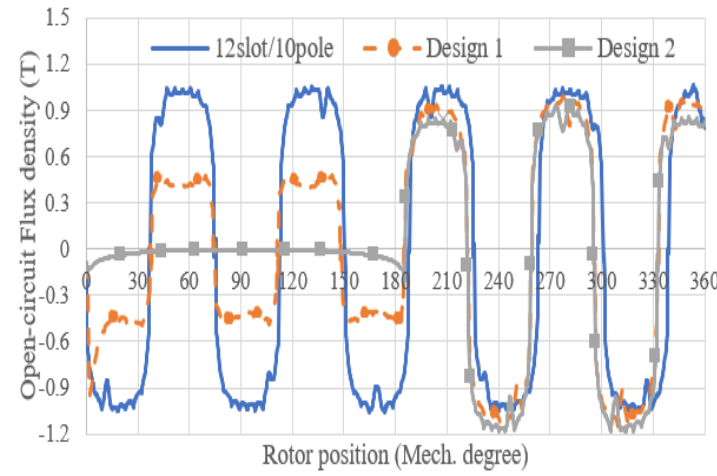

b) Airgap flux-density

Figure 7. No-load condition

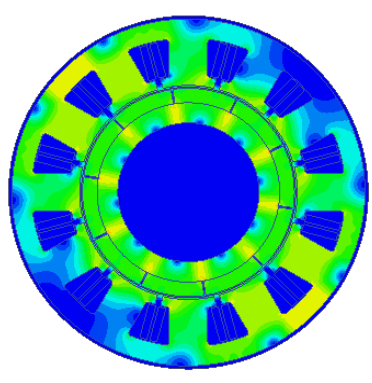

a) 12-slot/10-pole

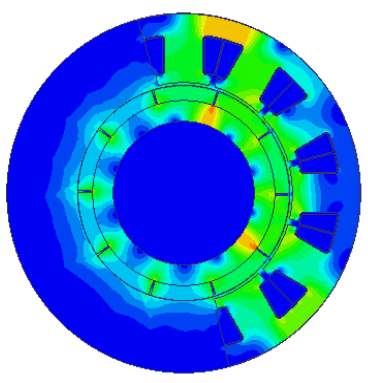

b) Design 1

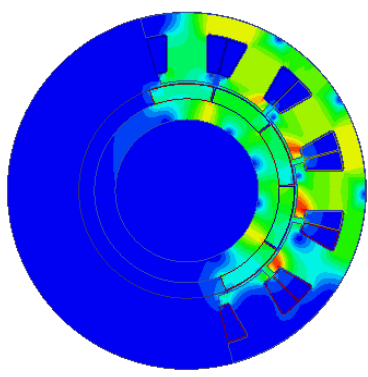

c) Design 2

Figure 8. Flux saturation level at no-load condition

\subsection{Back-emf}

Phase back-emfof all designs are shown in Figure 9. The prediction is obtained at $100 \mathrm{rpm}$ rated speed. The peak value for actual design is $6.3 \mathrm{~V}$. As mentioned earlier, the number of cycle corresponds to the number of pole-pair which completes 1 mechanical rotation. In general, trapezoidal phase back-emf indicates a trapezoidal current is a better choice than sinusoidal excitation current for a constant electromagnetic torque. Due to symmetric distribution of permanent magnet flux-linkage, Design 1 has a balanced back-emf profile than the Design 2. The odd numbers of magnetic pole on rotor in Design 2 distorts the back-emf, leading to an asymmetric back-emf. However, the peak induced back-emf for both designs dropped by $50.3 \%$ than the actual design. According to Figure 9(b), the rise of higher multiple order harmonics i.e. $3^{\text {rd }}, 5^{\text {th }}$ and $7^{\text {th }}$ indicates nonsinusoidal waveform and dented peaks. 


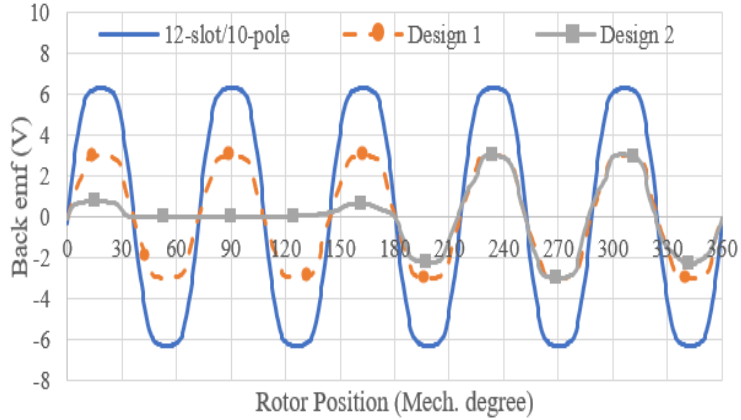

a) Phase back-emfs

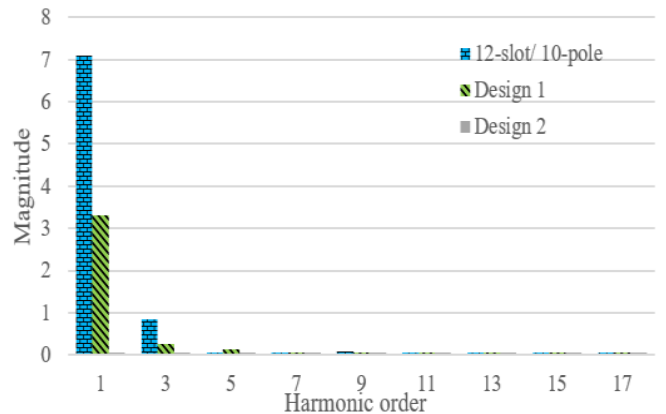

b) Harmonics components

Figure 9. Back-emf analysis

\subsection{Cogging torque}

An interaction between rotor magnetic flux and slotted structure of stator at no-load condition results a cogging torque. The cogging frequency, $\operatorname{Cog}_{\text {freq }}$ and cogging factor, $C_{T}$ for each PM motors are calculated using equation (9) and equation (10) respectively.

$$
\begin{aligned}
& \operatorname{Cog}_{\text {freq }}=\frac{\operatorname{LCM}\left(N_{s}, 2 p\right)}{360^{\circ}} \\
& C_{T}=\frac{N_{s} x N_{p}}{\operatorname{LCM}\left(N_{s,}, 2 p\right)}
\end{aligned}
$$

where $L C M, N_{s}$ and $2 p$ are the lowest common multiple, slot numbers and pole numbers respectively. Generally, high cogging torque and cogging factor in PM motors result in high torque ripple and vibration phenomenon. Figure 10 compares profiles of cogging torque when zero current excitation is applied. The actual design has a constant peak-to-peak cogging torque $0.1 \mathrm{Nm}$ with 60 cogging cycle. However, situation changes for Design 1 and Design 2 respectively. The cogging torque profile changes when asymmetric designs on stator and rotor are introduced. This is comfirmed by the change of cogging cycles in the Design 1 and 2. The Design 2 would be more severe as the cogging torque getting bigger up to $1.3 \mathrm{Nm}$ which is about $10 \%$ of the desired output torque.

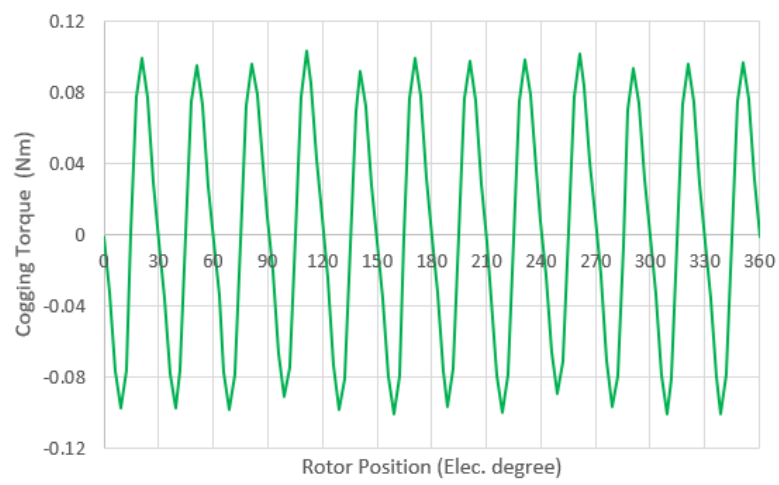

a) Actual design

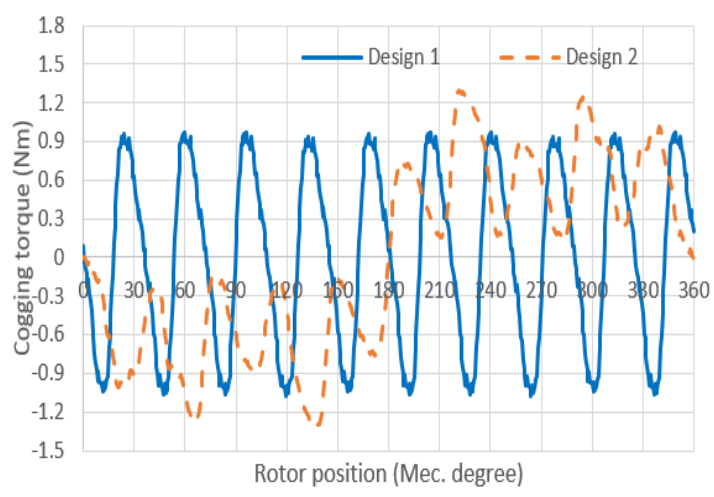

b) Design 1 and Design 2

Figure 10. Cogging torque analysis

\subsection{Electromagnetictorque}

Output torque performance of all designs are shown in Figure 11. The motor designs are excited with trapezoidal current, $120^{\circ}$ commutation. The commutation has six-steps in 1 electrical cycle which finally results 5 electrical cycles for 1 mechanical rotation. The actual design results an average torque of $10.3 \mathrm{Nm}$ 
and $22 \%$ torque ripple. While the Design 1 and 2 result in reduced average torque by $53 \%$ and $80 \%$, equivalent to $4.8 \mathrm{Nm}$ and $2.0 \mathrm{Nm}$ respectively. The output torque profile also changes when asymmetric designs on stator and rotor are introduced. This is comfirmed by the change of torque cycles in the Design 1 and 2. The Design 1 shows a reduction of average torque, i.e. $\sim 50 \%$, while the Design 2 shows an alternating trend as the torque has inconsistent peaks. The torque ripples for Design 1 and 2 are around $60 \%$ and $400 \%$ respectively.

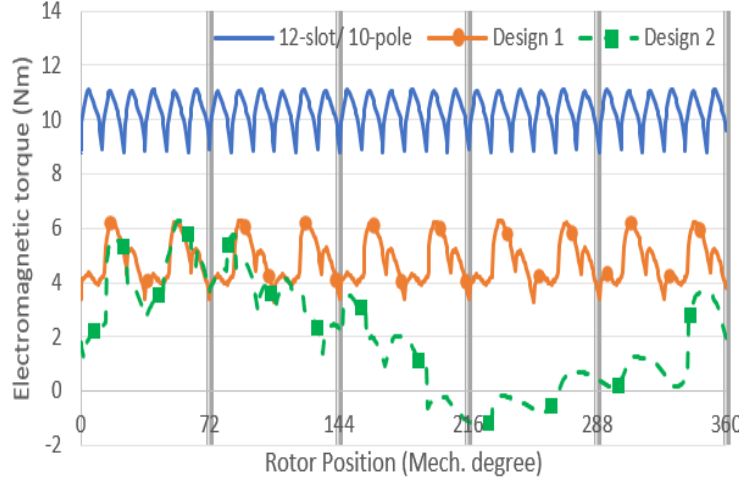

a) Static torque

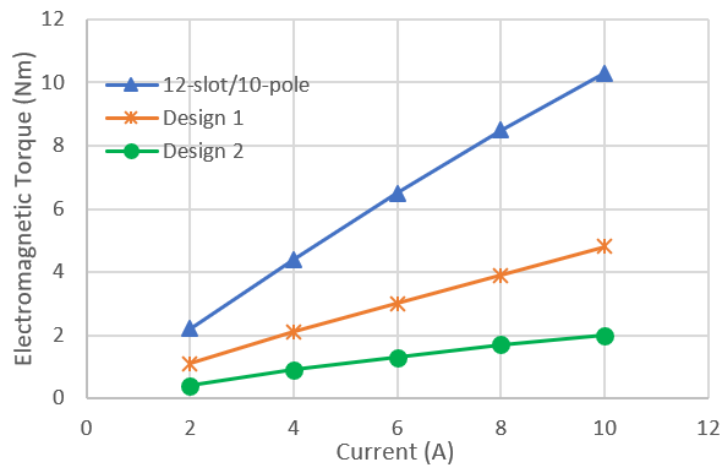

b) Average torque vs phase current

Figure 11. Output torque analysis

\section{CONCLUSION}

From the investigation, the overall weight in PM motors is theoretically can be reduced by removing partial dimension in axial and/or radial direction. However, machine performance may deteriorates as asymmetric back-emf and output torque are unavoided. A proper design procedure that includes parameter optimization and intelligent switching for optimum current excitation is required to restore the desired torque.

\section{ACKNOWLEDGEMENTS}

The authors would like to thank UniversitiTeknikal Malaysia Melaka (UTeM) for providing UTeMZamalah Scheme, UTeM.29.02/600-1/9/5 Jld.6 (149) for this research.

\section{REFERENCES}

[1] Chapman S. J., Electrical Machinery Fundamental 2005, $4^{\text {th }}$ ed., New York: McGraw-Hill.

[2] Santiago et al., "Electrical Motor Drivelines in Commercial All Electric Vehicle: A Review", IEEE Transactions on Vehicular Technology,2015; 61(2); 475 - 484.

[3] J. Fenton and R. Hodkinson, Lightweight Electric/Hybrid Vehicle Design: Automotive Engineering Series 2001, Chapter 1: Current EV design approaches: Elsevier Butterworth-Heinemann.

[4] Yime, E. et al, "Design of a brushed DC motors PID controller for development of low-cost robotic applications",2014 III International Congress of Engineering Mechatronics and Automation (CIIMA).

[5] Vaijayanti, "Robotic Arm Control using PID Controller and Inverse Kinematics", International Journal of Engineering Development and Research, 2017; 5(1);1571 - 1579.

[6] Agbaraji\&Inyiama, "A Survey of Controller Design Methods for A Robot Manipulator in Harsh environment",European Journal of Engineering and Technology, 2015; 3(1); 64 - 73.

[7] Amin R. et al, "Modelling and Control of DOF Robot Arm using Fuzzy Logic Supervisory Control",International Journal of Robotics and Automation, 2013; 2(1); 56 - 68

[8] Gieras J. F. \& Wing M., Permanent Magnet Motor Technology 2002. $2^{\text {nd }}$ ed. New York: Marcel Dekker, Inc. pp: 453-458.

[9] Harshvardhan R. et al,"Stepper Motor: A Review on Theory and Fundamental",International Journal of Emerging Trends in Science and Technology. 2015; 2(6); 2546 - 2551.

[10] Balai P. N. \&Talati J. A., "Open Loop Motion Control of Stepper Motor for Video Surveillance System",International Journal of Novel Research in Electrical and Mechanical Engineering, 2015; 2(1); 41 - 46.

[11] Tarnini, M. Y., "Fast and Cheap Stepper Motor Drive",2015 International Conference on Renewable Energy Research and Applications (ICRERA).

[12] Aranjo, B. et al, "Stepper Motor Drives for Robotic Applications",2012 IEEE International Power Engineering and Optimization Conference, 6 - 7 June 2012. IEEE Publisher. 
[13] Aswinbalaji, "Wireless Voice Controlled Robotic Arm"International Journal of Engineering Technology in Computer Sciences \& Electronics, 2012; 12(1); 33 - 38.

[14] Bhale C. et al. "Analysis of Stepper Motor Drivers",International Conference on Science and Engineering for Sustainable Development, 2017; $251-256$.

[15] Edvard, 2013. Few Words About Stepper Motor (Advantages, Disadvantages and Classification). Available at https://electrical-engineering-portal.com/few-words-about-stepper-motor-advantages-disadvantages-andclassification. [Assessed on 10 September 2018].

[16] Manoj et al, "FEA of a High Efficiency Brushless DC Motor Design”, International Journal of Applied Engineering Research, 2017; 12(1); 11417 - 11423.

[17] Shirish \& Jain, "Modelling and Simulation of Three Phase BLDC Motor for Electric Braking Using MATLAB/SIMULINK",2017; 5(1); 48 - 53.

[18] Shivraj\& Archana, "Mathematical Modelling and Simulation of Three Phase BLDC Motor Using MATLAB”,International Journal of Advance in Engineering \& Technology, 2014; 1426 - 1433.

[19] Sanadhya N. et al, "Reliability of Permanent Magnet Brushless DC Drives using IGBT's",International Journal of Innovative Research in Science, Engineering and Technology, 2013; 2(3); 772- 780.

[20] Yang M. et al, "A Cost-Effective Method of Electric Brake with Energy Regeneration for Electric Vehicle",IEEE Transaction on Industrial Electronics, 2009; 56(6); 2203 - 2212.

[21] Priti S. M. et al, "Selection and Design of BLDC Motor for Different Applications",International Journal of Electrical Electronics, 2015; 4(1); $114-119$.

[22] Masataka M. \& Kan A., "Efficiency Comparison between brushless DC Motor and Brushless AC Motor Considering Driving Method and Machine Design",IEEJ Journal of Industry Application, 2012; 2(1); 79 - 86.

[23] Tae Y. L. et al, "Motor Design and Characteristics Comparison of Outer Rotor Type BLDC Motor and BLAC Motor Based on Numerical Analysis",IEEE Transaction on Applied Superconductivity, 2016; 2(4); 1 -6.

[24] J. R. Hendershot \& T. J. Miller, "Design of Brushless Permanent Magnet Machines" in Motor Design Books, USA: Florida, 2010.

[25] Cavagnino A. et al, "A comparison between the Axial Flux and the Radial Flux Structures for PM synchronous Motors”. IEEE Transactions on Industry Applications, 2002; 38(6);1517 - 1524.

[26] Chen A. et al., "Performance Comparisons Among Radial Flux, Multi-stage Axial Flux and Three-phase Transverse Flux PM Machines for Downhole Application”, IEEE International Electric Machines and Drives Conference, 3 -4 May 2009.

[27] Indirajith K. \& Kumar R. B., "Comparative Study of The Transverse, Axial and Radial PM Synchronous Motors for Wind Application", International Journal of Electrical and Electronics Engineers, 2017; 9(1); 944 - 955.

[28] Amit N. P. et al, "Influence of Difference Type of Stator Slots on Torque Profile of Surface Mounted Pm Motors",International Journal of Computer Applications in Engineering Sciences, 2014; 5(2);40 - 42.

[29] Ilka R. et al, "Design of Slotless BLDC Motor for Eliminating Cogging Torque",Journal of World's Electrical Engineering and Technology, 2014; 3(2); 67- 73.

[30] Jung M. S. et al, "A Study on Brushless DC Motor for High Torque Density”,International Journal of Mechanical and Mechatronic Engineering, 2011; 5(10); 2084 - 2088.

[31] Sharkh, S. M., \& Lai, S. H., "Slotless PM Brushless Motor with Helical Edge-Wound Laminations",IEEE Transactions on Energy Conversion, 2009; 24(3); 594-598.

[32] M. Nicole et al., "Brushless DC Micro Motor with Surface Mounted Permanent Magnet", Journal of Revue Roumaine des Sciences Techniques, 2014; 3(1); 237-247.

[33] G R. Puttalakshmi\& S. Paramasivam, "Electromagnetic Flux Analysis of Permanent Magnet Brushless Dc Motor using Magnet Software", International Journal of Engineering and Technology, 2013; 5(1); 3215-3222.

[34] Bianchi, N. et al, "Comparison of PM Motor Structures and Sensorless Control Techniques for Zero-Speed Rotor Position Detection”,IEEE Transactions on Power Electronics, 2007; 22(6); 2466-2475.

[35] J. R. Hendershot \& T. J. Miller, "Design of Brushless Permanent Magnet Machines" in Motor Design Books, USA: Florida, 2010.

[36] Brushless DC (BLDC) Motor Fundamentals Application Note; AN885, Microchip: AZ, USA. 2003.

[37] Burger, F. et al, "New Single Chip Hall Sensor for Three Phases Brushless Motor Control", Sens. Actuate. A-Phys., 2000; 81(1); 320 - 323.

[37] Padalkar, A., "Speed and position control of BLDC motor using internal hall sensors and hardware design", 2015 International Conference on Information Processing (ICIP), 16-19 December 2015. Published by IEEE.

[38] Murugun M. et al, "Rotor Position Sensorless Control of BLDC Motor based on Back emf Detection Method",TELEKOMNIKA Indonesian Journal of Electrical Engineering, 2005; 14(2); 222- 227.

[39] Pandey K. K. \&Bhadoriya J. S., "Improved Back Emf of Rotor Position Detection of a Sensorless BLDC Motor",International Journal of Science \& Technology, 2014; 3(1); 143 - 148.

[40] Hwang C. C. et al, "Design and Analysis of a Brushless DC Motor for Applications in Robotics", IET Electric Power Applications, 2012; 6(1); 385-389.

[41] Shaikh T. F. \&Sankeshwari S.S., "Torque Estimation of BLDC Motor Using SMC Techniques",International Journal of Modern Engineering and Research Technology, 2018; 5(3); 136 - 140.

[42] Manikandan et al, "dSPACE Real Time Implementation of Fuzzy PID position Controller for Vertical Rotating Single Link Arm Robot using Four Quadrant BLDC drive",ActaScientiarum, July - Sept. 2017; 39(3); 301 - 311.

[43] Krishnan P. H., \& Arjun M., "Control of BLDC Motor Based on Adaptive Fuzzy Logic PID Controller", 2014 International Conference on Green Computing Communication and Electrical Engineering (ICGCCEE), 6 - 8 March 2014. IEEE Publisher. 
[44] Zolkapli Z. Z. et al, "Torque Ripple Minimization Technique in Fractional-slot PM Brushless Machines", 2014 IEEE Conference on Energy Conversion (CENCON), 13 -14 October 2014. IEEE Publisher.

[45] Shirish V. \& Jain A. M., "Modelling and Simulation of Three Phase BLDC Motor for Electric Braking Using MATLAB/SIMULINK",International Journal of Electrical, Electronics and Data Communication, 2017; 5(7); 48 53.

[46] Priya C. M. et al, "Performance Analysis of BLDC Motor using Intelligent Controller",International Journal of Electrical and Electronics Engineering, 2017; 11 - 15.

[47] Sudhanshu M. et al, "Modelling and Simulation of BLDC Motor using MATLAB/SIMULINK Environment", International Research Hournal of Engineering and Technology, 2015; 2(8); 199 - 203.

\section{BIOGRAPHIES OF AUTHORS}

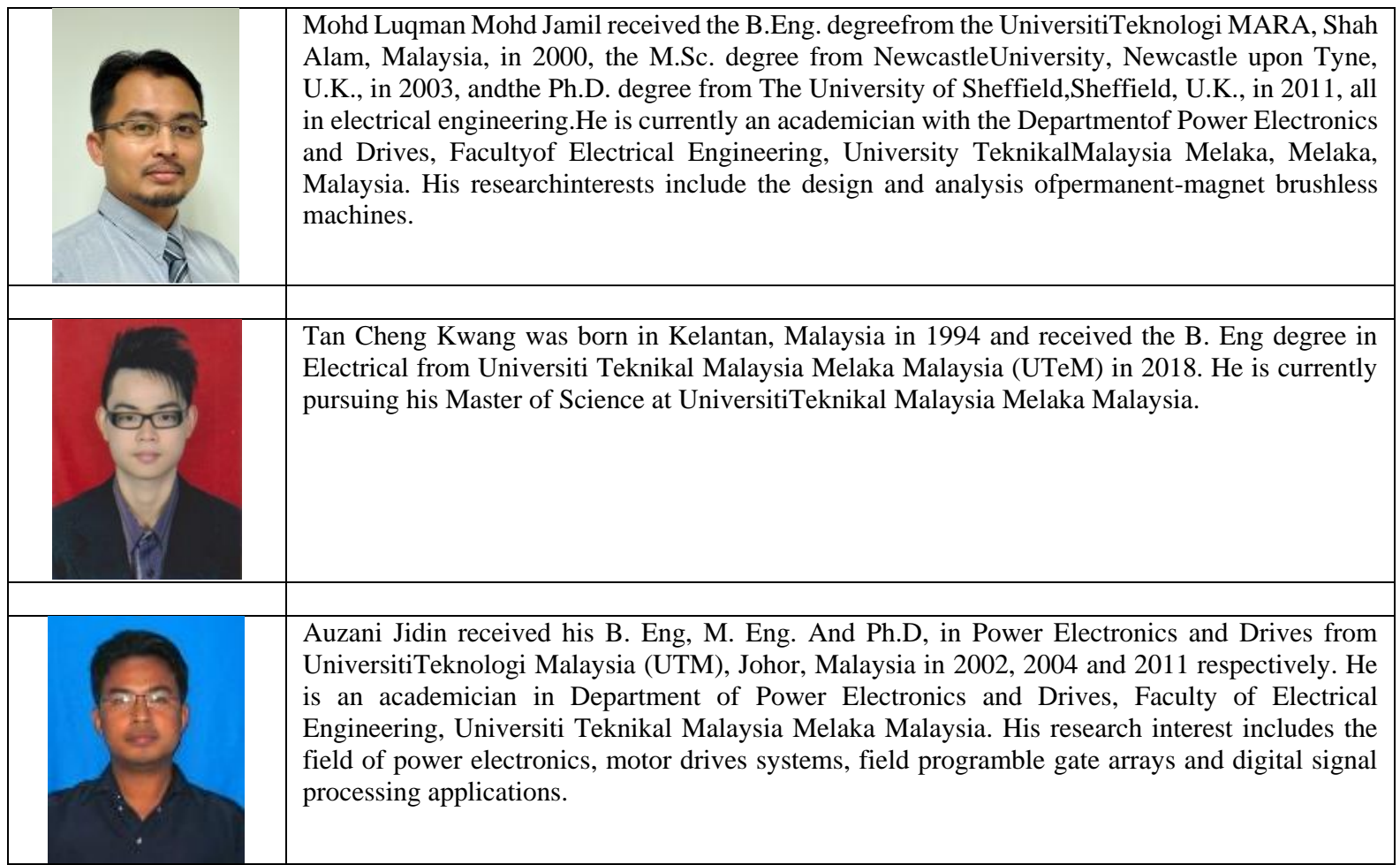

